\section{Sexual communication}

San Francisco being the city of love-and sex, well, being sex-the symposium on human sexual communication was crowded out. Appropriately enough it was held in one of the hotel bedrooms. The intention of the symposium was, I think, to help drug therapists become aware of their own inhibitions so that they would be able both to understand and to communicate about their patients' sexual difficulties. The problem was that not too many of the attending therapists seemed to have these types of inhibitions, and Americans being a warmblooded, friendly people, the atmosphere in the overcrowded hotel suite soon began to change into rather less than that of a clinical workshop.

The five days were capped by two outstanding fund-raising parties; one on behalf of a society for the legalisation of marijuana and the other for the Haight-Ashbury Free Medical Centre in San Francisco, which continues to perform such an excellent service for the health of the addicts in the area. Both were extremely gay, in the traditional sense of the word; the homosexuals of both types (perhaps "homoperson" in current parlance) having already had full exposure at the conference.

It is speculative to ask whether these techniques of inner awareness have now reached their peak. There is no sign at present that the end of this latest American obsession is close at hand. Even its physical counterpart, jogging, has been advocated as a means to achieve a meditative state, although I believe it takes 25 minutes and a distance of over two miles to reach it. Inner space has even hit the New England fournal of Medicine, where a series of articles has recently reviewed the relaxation response. A book on tennis and another on golf use inner vision and contemplation to achieve success and life's contentment.

America, as it passes its first post-bicentennial birthday, is still contemplating its navel. Perhaps by the time the next conference is held in this city the underlying guiding principle of these techniques will have unified into a more general approach to positive health. Which way then ? In this matriarchal society, in which female liberation to a male chauvinist like myself feels like female supremacy, perhaps it will be male emotional liberation. Women certainly had their voice at this conference. I felt a little hurt at being excluded from a symposium on the lesbian in society, but quickly recalled that the same ban exists for women in many English gentlemen's clubs.

Drug abuse among women is rapidly increasing in the USA, whether it is of the legal medically sanctioned type caused by the current tremendous quantity of prescribed psychotropic drugs or the illegal purchase of these and other drugs on the street. Many women's groups blame this trend on the stormy transition of modern women from their traditional role of care-provider to emancipated equality. Many women experience an identity crisis that forces them to find an immediate escape from their mental turmoil through drugs.

Nevertheless, whatever the problems of modern woman may be, in this society it is the poor, exposed, middle-class man that concerns me. There is a daily fight of role-protection and advancement-a necessity to achieve success in the eyes of their peers and family. Books and articles on executive stress abound, and many a man's battle of ego-protection at the office is continued on his return to the family and his emancipating wife. Once women have finally established their role in the new society, perhaps men will be able for the first time to be emotional; to be frail; to take a day off well from work instead of a day off sick; and eventually just to be themselves, equal to women. But that's a subject for another workshop in the future.

(Accepted 13 fuly 1977)

\title{
Aspects of Research
}

\section{Applications submitted to regional research committees in 1976 and their outcome}

\author{
B T WILLIAMS
}

British Medical fournal, 1977, 2, 944-946

\section{Summary}

In 1976 regional research committees in England and their equivalent in the Welsh Office judged 608 proposals for funding under the locally organised research scheme. Of these, 521 were new proposals and 87 were resubmissions. Medically and dentally qualified applicants made $451(87 \%)$ of the new proposals; nearly two-thirds came from teaching areas and $21 \%$ from staff of academic departments. Two hundred and ninety new proposals were approved, 154 rejected, and 77 were referred back for modification. Approval was commoner for applications from teaching areas, from medical staff, and for the

Trent Regional Health Authority, Sheffield S10 3TH

B T WILLIAMS, MD, MFCM, specialist in community medicine (information and research) less expensive projects. Some regional committees did not support research into the organisation of health services. Under a quarter of the resubmitted projects were rejected.

The scheme is not yet used by a wide range of healthcare professions. Medical staff in teaching areas still use it most. In some regions prospective researchers, especially those without previous experience, need a comprehensive and easily identifiable counselling service, so that the fund may be exploited in the way originally intended and the number of unsuccessful proposals reduced.

\section{Introduction}

In 1975-6 the Department of Health and Social Security spent $£ 1.86$ million $\left(8^{\circ}{ }_{0}\right.$ of its entire research budget) on the locally organised research scheme." This scheme aims "to foster the research spirit in medicine" and "to facilitate the discovery and encouragement of local talent." 2 The research, which is 
organised and managed locally, has to be related to Health Service practice, and the fund is administered by the 14 English regional health authorities. In Wales, a similar scheme is administered by the Welsh Health and Social Work Research Development Committee. This functions according to the same code of practice, and is hereafter included in the term "regional research committees."

The scheme, which started in 1958, was reviewed by a joint working party of the DHSS, Welsh Office, and the Medical Research Council, which reported in $1974 .^{3}$ It found that the scheme was used mainly by doctors in the hospital service to prosecute clinical research. The working party reaffirmed that the scheme should support a wide range of research, in the community as well as in hospital, and recommended that it should be widely publicised among the health professions in all parts of the Service, and each regional health authority should be advised by a widely representative research committee that met regularly.

The Department of Health accepted these recommendations and embodied them in a code of practice published as a health services circular. ${ }^{2}$ I will describe the effect of these recommendations on the types of application submitted in 1976 to regional research committees in England and Wales.

\section{Method}

Most regional research committees met three or four times during 1976. Details of all the research proposals appearing on the agenda of those meetings were abstracted on to data collection sheets by local administrative staff. These data were transcribed on to cards and analysed manually. The data were supplemented by interviewing the administering officers of regional health authorities and the Welsh Office.

\section{Results}

During the year 622 proposals were placed before regional research committees (14 in England, one in Wales). Six were withdrawn before they could be considered, and eight either received no consideration at the particular meeting because it was clear that funds would not be available to meet the cost, or only partial consideration pending receipt of a referee's report.

Of the 608 proposals that were fully judged, $521(86 \%)$ were new proposals and $87(14 \%)$ were resubmissions of proposals that had been referred back for modification. In $451(87 \%)$ of the new proposals the principal applicant was medically or dentally qualified (most applications were made in one name but when more than one applicant was listed on a proposal the first-named was selected as the principal applicant). Hospital doctors continued to dominate the scheme in 1976. In comparison the response from each of the other health-care professions was small (table I).

Only 20 of the 98 area health authorities in England and Wales are teaching area authorities. Nearly two-thirds (337) of the new proposals came from applicants employed in these teaching areas, however, and only two of these were from non-teaching districts of the teaching areas.

Staff of academic departments were the principal applicants in 109 $(21 \%)$ cases. This figure probably underestimates the use made of the scheme by academics since, in three regions, research committees of the teaching hospitals draw on the locally organised research fund to finance approved projects put forward by staff of these hospitals. In only one of the regions are these proposals re-examined by the regional research committee and therefore the teaching hospital proposals from that region only are included in this analysis. In each of the three regions concerned the greater part of the region's estimate of expenditure and the subsequent DHSS allocation for locally organised research is made up of the teaching hospital component. If the two regions whose research committees did not re-examine the teaching hospital proposals are excluded, the 109 applications from academic staff made up $23 \%$ of the remaining 478 new proposals.

Adjudication of the 521 new proposals by the various regional research committees resulted in $290(56 \%)$ being approved for funding, $154(30 \%)$ being rejected, and $77(15 \%)$ being referred-usually back to the applicants for modification after taking appropriate advice, but occasionally to an independent assessor for an expert opinion. The approved projects were not all accepted in the form in which they
TABLE I-Health care profession of new applicants from 14 English regions and Wales for locally organised research grants, 1976

\begin{tabular}{|c|c|c|c|c|c|c|}
\hline \multicolumn{6}{|c|}{ Profession } & \multirow{2}{*}{$\frac{\text { No of applications }}{439}$} \\
\hline \multirow{2}{*}{\multicolumn{2}{|c|}{ Medical . $\ldots$}} & .. & .. & $\ldots$ & & \\
\hline & & .. & $\therefore$ & . & $\ldots$ & \multirow{3}{*}{$\begin{array}{rr}411 & 439 \\
18 & \end{array}$} \\
\hline General pr & actitioners & .. & $\ldots$ & . & $\ldots$ & \\
\hline \multicolumn{2}{|c|}{ Community physicians } & .. & . & .. & $\ldots$ & \\
\hline Dental & . $\quad \ldots$ & .. & $\therefore$ & $\therefore$ & $\therefore$ & 10 \\
\hline Nursing & .. & .. & $\ldots$ & $\ldots$ & .. & 7 \\
\hline \multirow{2}{*}{\multicolumn{4}{|c|}{$\begin{array}{l}\text { Sclentihic } \\
\text { Professions supplementary to medicine }\end{array}$}} & $\therefore$ & $\ldots$ & \multirow{2}{*}{32} \\
\hline & & & & $\ldots$ & $\therefore$ & \\
\hline Psychology & . $\quad .$. & .. & $\ldots$ & $\ldots$ & . & 12 \\
\hline Pharmacy & .. & .. & $\ldots$ & $\ldots$ & $\ldots$ & 3 \\
\hline Social science & .. & .. & $\ldots$ & .. & .. & \multirow{2}{*}{3} \\
\hline Speech theral & . & .. & .. & . & . & \\
\hline Radiography & & .. & . & . & . & 1 \\
\hline Administratio & n/statistics & . & .. & .. & . & \multirow{2}{*}{$\begin{array}{l}5 \\
3\end{array}$} \\
\hline Not known & .. & . & $\ldots$ & . & . & \\
\hline \multicolumn{6}{|c|}{ Total } & 521 \\
\hline
\end{tabular}

TABLE II-Factors associated with outcome (new proposals)

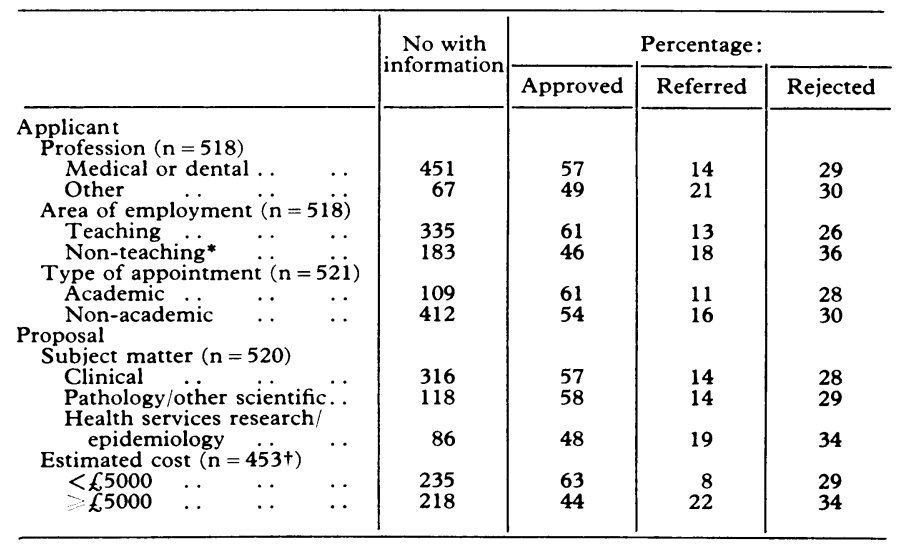

*Includes two proposals from non-teaching districts of teaching areas. +Excludes one RHA that provided information on costs approved, not costs estimated.

were submitted. Sometimes only a part of the sum of money requested was agreed, or approval was given only for an initial period of study, further funding depending on the production of a satisfactory progress report.

The main reason for proposals being rejected was that they lacked merit ( 71 cases). Other reasons were that the subject matter of the research (17), or the scale in time or cost or both (13) were outside the limits suggested by the code of practice that governs the administration of the scheme ( $£ 15000$ total cost, three years' maximum duration). In 32 cases the reason for the rejection was not stated. The remaining cases were rejected because the proposal was more appropriately classed as a service function (7); the nature of the research lent itself to funding from a different (usually larger) source, such as the Medical Research Council (10); or that the subject matter of the research was known to have been covered adequately by other researchers (4). Lack of finance was not specifically mentioned as a reason for rejection but officers administering the scheme cited ways in which this factor operates indirectly. A proposal on whose merits a committee is divided may be granted support if the sum of money remaining unallocated is relatively large, whereas on another occasion funds may be nearly exhausted and the project may be rejected in favour of others. Similarly, a costly project may be accommodated if ample funds are available but when finance is restricted it may be rejected with the recommendation that a specified alternative source of funding is sought.

The largest differences in the proportions approved were in respect of the type of area in which the applicant was employed, those from teaching areas being more successful, and costs, the less expensive projects being more readily funded. Medical and academic applicants were slightly more successful than their non-medical or non-academic counterparts. The subjects least likely to attract support were research into the organisation of health services and epidemiological projects. These projects tended to be among the most expensive, but an added factor was that some research committees did not regard the locally organised research scheme as appropriate for funding health services research (table II)

The outright rejection rates were comparable among medical and non-medical and among academic and non-academic applicants. They 
varied little in the subject matter of the proposals and estimated costs. The largest difference was in the applicant's area of employment-those from non-teaching areas being less successful. Projects in all categories were more commonly rejected than deferred, and the patterns of decision were in sharp contrast. Categories with higher percentages of approved projects tended to have lower percentages referred, and vice versa, whereas the percentages rejected were similar for all categories. This was particularly true in relation to cost. Committees were often cautious about letting expensive projects through unmodified. In some cases the applicant had to cut his costs, in others substantial methodological alterations were demanded to justify the expenditure.

Of the resubmitted proposals considered by regional research committees in 1976, 57 were approved, 10 referred, and 20 rejected. Thus a project that is not turned down outright at the first submission has a good chance of being accepted in due course-although in the present instance 10 proposals needed even further modification.

\section{Discussion}

Members of the joint working party were concerned that the range of research workers benefiting from the locally organised research scheme was so limited. Despite steps taken to widen eligibility little has altered. Demand still arises predominantly from doctors and from teaching areas, and this despite strenuous efforts by some regional health authorities to publicise the scheme widely among the eligible disciplines.

Certain explanations suggest themselves. Firstly, perhaps too little time has elapsed since the issue of the circular ${ }^{2}$ for much change to result. Secondly, most instruction during medical training is itself based on research findings, and medical students are reared in an ethos of inquiry and challenge. By comparison, training of NHS staff in the technical field, in the professions supplementary to medicine, and to some extent in nursing, is more in the nature of imparting a craft-learning to execute technical procedures efficiently. This is not to say that a spirit of inquiry does not exist in these professions: it is more a matter of how to discover and develop this aptitude.

Whereas doctors can usually identify within their profession experienced and accessible sources of help with formulating research proposals, similar sources may not exist for or be recognised by other professionals. While the locally organised research fund enables regional health authorities to finance suitable proposals from non-medical sources, for the facility to be exploited the authorities may have to publish each year, along with details of their scheme, a list of individuals and academic departments within their regions who are willing to assist with the formulation of research questions and the development of research methodologies. Certain members of academic departments of community medicine already hold contracts with regional health authorities, and research counselling forms part of the service they provide. Members of regional research committees often themselves provide a counselling service to intending applicants, but at the end of 1976 more than three-quarters (158) of the 203 members of the 15 research committees were doctors or dentists, and in two regions the research committees were made up entirely from these professions, so that the breadth of advice available from this source was limited. Moreover, the membership of nearly all these committees had already been revised as a result of the circular. ${ }^{2}$ Thus the chicken and egg question arises, in which there is little point in diversifying the membership of committees because the types of application dealt with are limited. But, with a professionally diverse committee not only is the range of recognisable sources of advice increased but also an awareness of the existence of the fund, and of the ways in which to exploit it, is disseminated by the committee members to others in their respective professions.

The concentration of teaching area applicants probably reflects the greater interest and opportunities for research in teaching institutions as well as the more generous staffing levels that are usually found in these areas. The pressure of work on staff in many non-teaching areas is such that many cannot contemplate undertaking any research. It should not be assumed, however, that little benefit accrues to non-teaching areas from this scheme. Some of the junior medical and other staff in teaching hospitals who are associated with research funded in this way will take senior posts in non-teaching areas, taking their experience with them.

The comparatively high proportion of proposals from nonteaching areas that were referred for modification once more argues the special need for applicants remote from teaching centres to have access to a prior counselling service, although the fact that nearly a third of all proposals were rejected suggests that there is wider scope for the use of counselling, particularly since the cause of rejection in over half the cases in which the reason was known was that the proposal lacked merit. If by "fostering the research spirit" is meant initiating an ability to inquire, then, clearly, the beginner needs guidance throughout his research. It may be equally justifiable, however, to include in the meaning of "foster" the concept of developing further an already active research spirit. On this interpretation the domination of the scheme by teaching institutions is acceptable.

Most regional research committees are unhappy about "research recidivists"-applicants who submit new proposals for funding as soon as support for their last project ends. Such proposals are sometimes generated to exploit the availability or to keep in employment technical staff originally supported by previous research grants.

The criteria of eligibility of subject matter varied among the regional research committees. This was most noticeable in health services research. One regional research committee emphasised its disfavour with such proposals by renaming itself the locally organised clinical research committee and this regional health authority and one other have established separate funds for supporting organisational research. While it is correct that studies undertaken in conjunction with a health authority's planning or monitoring functions should not be funded by the scheme, it appeared that even when the titles of proposals suggested methodological innovations that might have become generally applicable, some regional committees rejected them as inappropriate.

As a result of the recommendation of the recent regional chairmen's inquiry into the working of the DHSS in relation to regional health authorities, ${ }^{4}$ the central earmarking by the DHSS of funds for the locally organised research scheme may cease and regional health authorities will themselves decide how much to allocate to the scheme. The factors governing the demand will not change, however (assuming the scheme retains its present character). In deciding their funding policies, authorities will have the opportunity to consider such questions as whether funds should be earmarked for particular professional groups or for particular fields of research, whether the teaching hospital share should be rationed, and whether preference should be given to research directly relevant to the needs of the region concerned. Authorities may also decide whether a formal counselling service should be introduced to minimise the risk of wasted effort and disappointment for the researcher and to help ensure the best results possible for the money invested.

I am grateful to the officers of DHSS, the regional health authorities, and the Welsh Office who provided the information for this study and who bore my persistent querying so courteously. The views expressed here do not necessarily represent those of the Trent Regional Health Authority.

\section{References}

1 Department of Health and Social Security, Annual Report 1975, Cmnd 6565. London, HMSO, 1976

2 Department of Health and Social Security, NHS Locally Organised Research Scheme, HSC(IS)148. London, DHSS, 1975.

${ }^{3}$ Joint Working Party on the Decentralised Clinical Research Scheme in England and Wales, Department of Health and Social Security, Welsh Office, Medical Research Council, Report. London, HMSO, 1974.

- Department of Health and Social Security, Regional Chairmen's Enquiry into the Working of the DHSS in relation to Regional Health Authorities. London, DHSS, 1976.

(Accepted 12 August 1977) 